\title{
Carcinogenic Epoxide
}

National Cancer Institute

\section{Source}

National Cancer Institute. Carcinogenic Epoxide. NCI Thesaurus. Code C45408.

A ring-shaped org anic compound that can potentially cause cancer in humans and consists of an oxygen atom bonded to two other atoms, usually of carbon, that are already bonded to each other. ( $\mathrm{NCl05)}$ 